\title{
Tecnologias na Educação Básica: a articulação da tecnologia digital com o ensino da Língua Portuguesa
}

Eduardo Menegais Maciel*

\section{Resumo}

O presente artigo apresenta resultados de uma pesquisa acerca da Escola Estadual de Educação Básica Anacleto Damiani, tendo como foco "A Articulação da Tecnologia Digital com o Ensino de Língua Portuguesa". A partir da Educação e da Tecnologia, que são marcos de grande influência na sociedade contemporânea, o professor tem grandes desafios em sua prática docente que, numa era de tantos recursos tecnológicos busca diversificar seus métodos para conseguir resultados mais eficazes no seu fazer pedagógico. No entanto, uma significativa reflexão pode ser realizada no sentido do uso da tecnologia educacional na formulação de metodologias do componente curricular de Língua Portuguesa ou em atividades interdisciplinares. Esta é uma análise documental a partir dos planejamentos anuais do Ensino Fundamental da disciplina de Língua Portuguesa e o Projeto Político Pedagógico da escola, e volta-se para a análise dos usos da tecnologia nas práticas pedagógicas nas aulas de Língua Portuguesa, numa escola pública estadual do município de Abelardo Luz/SC. Apresenta-se, também, quais são as tecnologias presentes no espaço constitutivo da escola e propõem-se alternativas/sugestões para o uso delas. Os dados encontrados apontam para uma articulação significativa do professor de Língua Portuguesa com os recursos presentes na escola, porém, para aprofundar mais esta pesquisa, faz-se necessário analisar cotidianamente a prática escolar dos professores de português da escola, ou de outro planejamento, como por exemplo, os planejamentos diários ou semanais, que se organizem com uma descrição mais detalhada de suas práticas de ensino para trabalhar e desenvolver as habilidades relativas à língua materna, neste caso, a Língua Portuguesa.

Palavras-chave: Educação. Tecnologia. Língua Portuguesa.

\section{Introdução}

O que se percebe na contemporaneidade é que um dos grandes desafios consiste no uso da tecnologia digital está no desenvolvimento de metodologias e práticas pedagógicas e a incorporação das tecnologias contemporâneas no dia a dia dos docentes,

* Universidade Federal da Fronteira Sul (UFFS) - Acadêmico do programa de pós-graduação (PPGE) - Mestrado em Educação - Campus Chapecó - SC. Brasil. E-mail: eduardomenegais397@gmail.com

https://doi.org/10.5335/rbecm.v5iespecial.12825

http://creativecommons.org/licenses/by-nc-nd/4.0

ISSN: 2595-7376 
discentes e todo o corpo que constituiu a escola. Nesse contexto, torna-se importante compreender o processo de incorporação dessas tecnologias na escola, particularmente pelo professor, pois esse conjunto de inovações, especialmente no campo da comunicação, pode contribuir na vinculação entre os contextos da escola, da vida do jovem aluno, do mundo do trabalho e da cultura contemporânea (SOARES, 2006, p. 39).

Não há mais como negar a existência da tecnologia digital nos espaços educacionais, é necessário investigar como esses mecanismos podem ser úteis no fazer pedagógico do professor da atualidade. Por esse motivo, o trabalho tem como finalidade analisar a articulação da tecnologia com a prática escolar do professor de Língua Portuguesa, pensando na possibilidade de constatar articulações com o ensino que ofereçam retornos significativos para o professor e para o aluno, tendo em vista as competências e habilidades que a disciplina de Língua Portuguesa busca estimular e desenvolver.

Dentro dessa orientação, o trabalho é documental, que é um tipo de pesquisa que consiste analisar materiais de naturezas que não receberam ainda um tratamento analítico que, neste caso, são os planejamentos anuais da disciplina de Língua Portuguesa e o Projeto Político Pedagógico da escola, e volta-se para a análise dos usos da tecnologia nas práticas pedagógicas nas aulas de Língua Portuguesa, numa escola pública estadual do município de Abelardo Luz/SC.

As informações contidas nessas fontes permitiram realizar uma abordagem qualitativa do fenômeno estudado, tendo em vista que é um método de investigação científica que concentra no caráter subjetivo do objeto analisado, estudando as suas particularidades e experiências individuais. Nesses documentos, planejamentos anuais do ensino fundamental e médio e o Projeto Político Pedagógico da escola, buscou-se analisar se o professor de Língua Portuguesa introduz a tecnologia no seu planejamento para o ensino da Língua Portuguesa e como o Projeto político Pedagógico da escola contempla o uso dessas ferramentas.

\section{Tecnologia digital: reflexões para o ensino do Português}

Um dos grandes desafios da escola, cada vez mais, é o de conseguir articular o meio tecnológico ao processo de ensino e de aprendizagem de maneira adequada. Afirma Moran (2007, p. 57), por exemplo, "Tudo o que passa na televisão é educativo, basta o professor fazer a intervenção certa e propiciar momentos de debate e reflexão". 
Outro aspecto a ser considerado é a aceitação de quem faz uso das tecnologias na educação. Sampaio e Leite (1999) enfatizam que, a tecnologia educacional deve servir de suporte à escola, de modo que atenda às necessidades humanas na era da informação. Mas para que a articulação desse suporte tecnológico com a educação possa se concretizar, o professor deve dominar e acreditar que possam servir de recurso no seu fazer pedagógico e, assim, criar condições que facilitem a aprendizagem do aluno. Assim, refere-se Sampaio e Leite (1999, p. 25),

[...] o professor estará criando condições para que o aluno em contato crítico com as tecnologias da/na escola consiga lidar com as tecnologias da sociedade sem ser por elas dominado. Este tipo de trabalho só será concretizado, porém, na medida em que o professor em termo de valoração e concretização de sua utilização (ou seja, por que e para que utilizá-las), quanto em termo de conhecimento técnico (ou seja, como utilizá-las de acordo a sua realidade).

As tecnologias podem dar suporte ao professor. O que é abstrato pode ser visualizado; o microscópico torna-se grande; o passado pode ser o presente, transformando o conteúdo em um material diversificado e atraente. O essencial é que as aulas obedeçam a uma cadeia de ideias que deixe o aluno orientado em relação ao que está aprendendo, e o ensino deve ser interligado. Segundo Moran (2007, p.02),

É preciso evoluir para se progredir, e a aplicação da informática desenvolve os assuntos com metodologia alternativa, o que muitas vezes auxilia o processo de aprendizagem. O papel então dos professores não é apenas o de transmitir informações, é o de facilitador, mediador da construção do conhecimento. Então, o computador passa a ser o 'aliado' do professor na aprendizagem, propiciando transformações no ambiente de aprender e questionando as formas de ensinar.

Em Língua Portuguesa, por exemplo, podem ser trabalhados textos utilizando apenas um computador e o programa Word; pode incluir comentários nos textos dos alunos sem alterá-los e depois pedir que revisem e reescrevam, pois quanto mais isso acontecer, mais o aluno perceberá que seu texto não é um produto acabado, mas algo que pode sempre ser melhorado e, com isso, vai adquirindo domínio na modalidade escrita da língua; pedir aos alunos que pesquisem na internet um texto narrativo e solicitar que mudem o gênero textual para poesia ou teatro, pois internet é uma fonte riquíssima e excelente aliada do professor de português; videoconferências, realizadas através de programas como o Skype e Google Meet, por exemplo, são particularmente úteis para o professor de Língua Portuguesa, que poderá acordar com professores de outros países que ensinam a língua em questão, em séries equi- 
valentes, para que os alunos possam conversar on-line. Sobre isso, as Orientações Curriculares Nacionais (2008, p. 174) colocam,

Deve-se observar que a adesão aos recursos tecnológicos, proposta nesta tendência pedagógica, é hoje largamente retomada na educação, particularmente em relação ao acesso à informática e à comunicação em rede (internet). Observação que nos permite chamar atenção no sentido de evitar os reducionismos do passado, desafio das propostas atuais.

Os aparatos tecnológicos também podem servir para incentivar a criança a gostar de ler e, assim, estimular o hábito de leitura. O professor pode propor leituras de diferentes autores, gêneros em computadores, tabletes, celulares. Pode também, criar um grupo de whatsApp, e-mail, e mandar semanalmente material para realizar leituras.

A utilização de produtos do mercado da informação: revistas, jornais, programas de rádio e televisão, home-pages, sites, correio eletrônico, redes sociais, possibilitam novas formas de comunicação e geram novas formas de produzir conhecimento. Essas mudanças nos processos de comunicação e produção de conhecimentos podem transformar a consciência individual, na forma de olhar o mundo, de modo geral, em sua atuação social. Para os PCNs (2008), a introdução das novas tecnologias no processo de ensino e de aprendizagem só tem sentido se contribuir para a melhoria da qualidade do ensino. A tecnologia digital deve servir para enriquecer o ambiente educacional, propiciando a construção de conhecimentos por meio de uma atuação ativa, crítica e criativa por parte de alunos e professores.

A base Nacional Comum Curricular - BNCC (2017) apresenta a tecnologia como fundamental, tanto que em sua organização um dos pilares é a cultura digital e como ela deve ser inserida no processo de ensino e aprendizagem. Nesse documento, que já está em vigor e é caracterizado como uma política de Estado, se apresentam duas competências gerais que estão relacionadas ao uso da tecnologia, a quarta e a quinta,

Competência 4: Utilizar diferentes linguagens - verbal (oral ou visual-motora, como Libras, e escrita), corporal, visual, sonora e digital -, bem como conhecimentos das linguagens artística, matemática e científica, para se expressar e partilhar informações, experiências, ideias e sentimentos em diferentes contextos e produzir sentidos que levem ao entendimento mútuo. Competência 5: Compreender, utilizar e criar tecnologias digitais de informação e comunicação de forma crítica, significativa, reflexiva e ética nas diversas práticas sociais (incluindo as escolares) para se comunicar, acessar e disseminar informações, produzir conhecimentos, resolver problemas e exercer protagonismo e autoria na vida pessoal e coletiva (BNCC, 2017, p. 09). 
Ainda, na BNCC, a tecnologia é citada entre os direitos de aprendizagem e desenvolvimento nas Competências específicas de área nos Ensinos Fundamental e Médio, bem como nos respectivos objetivos de aprendizagem e desenvolvimento e habilidades. O objetivo da tecnologia no Ensino Fundamental é no sentido de os alunos receberem orientação dos professores para que consigam usufruir da tecnologia de forma consciente, crítica e responsável, tanto no contexto de sala de aula quanto para a resolução de situações cotidianas. No Ensino Médio o objetivo está ligado a um papel mais proativo no processo de aprendizagem e no uso das tecnologias, estando apto a um maior aprofundamento no letramento, linguagem e cultura digital como um todo.

\section{A tecnologia digital e a docência: reflexões sobre o ppp e o planejamento do professor de Português}

Com o presente trabalho analisa-se a articulação da tecnologia com o ensino da Língua Portuguesa, na Escola de Educação Básica "A", de "B” - SC. Para essa discussão analisou-se o PPP da escola e os planejamentos da disciplina de Língua Portuguesa do ensino fundamental: $6^{\circ}, 7^{\circ}, 8^{\circ}$ e $9^{\circ} \mathrm{s}$ anos.

O projeto político pedagógico da escola adota uma concepção de currículo flexível em constante processo de construção, elaboração, inovação - inacabado. Aponta para a importância da formação continuada do professor, a qual é uma das ações imprescindíveis do professor-tecnológico, tendo em vista que, para utilizar a tecnologia na escola, bem como nas práticas pedagógicas dos professores, é necessário partir do pressuposto que o professor deve ser atualizado e bem preparado, pois, a formação continuada de professores e a promoção de projetos que evidenciam essa diversidade têm uma enorme importância para a construção de diálogos com as diferentes culturas presentes na comunidade escolar (PPP - EEB Básica Professor Anacleto Damiani, 2018).

Em seu percurso formativo, numa perspectiva de concepção de formação integral, apresenta-se a educação integral como algo que não se limita à instituição escolar, mas um acesso a outras dimensões, como à saúde, ao esporte, à inclusão digital e à cultura e que a escola deve estabelecer um diálogo entre esses setores, sendo eles um conjunto de apropriações necessárias para a produção do conhecimento. Nesse sentido, a escola vai além de repassar o conhecimento científico, ela tem como 
objetivo introduzir os alunos em outras esferas da sociedade e, para isso, o acesso às tecnologias digitais é fundamental.

O laboratório de informática da escola possui uma boa estrutura física e de equipamentos, com 19 computadores com acesso à internet, três projetores multimídia, uma rádio escola completa, coordenada pelos alunos do ProEMI - Programa do Ensino Médio Inovador ${ }^{1}$ - que permite comunicação em tempo real com toda a comunidade escolar. A sala de informática, assim como os demais recursos, é bastante utilizada pelos alunos e professores, principalmente para a pesquisa, apresentação de trabalhos e desenvolvimento e planejamento das aulas, porém, cada professor organiza sua aula e utiliza o laboratório sem nenhum auxílio, pois a partir do ano de 2017 os profissionais de informática foram retirados das escolas estaduais de Santa Catarina. Agora, cada professor organiza sua aula e utiliza o laboratório sem nenhum auxílio.

O PPP traz o uso da tecnologia de informação e comunicação como meio bastante importante para o processo de ensino e de aprendizagem, tendo em vista que o laboratório de informática é um espaço que permite inúmeras possibilidades de pesquisa, comunicação e busca por novas informações, contribuindo para a realização de trabalhos em grupos, individuais e no desenvolvimento de projetos.

No plano de ensino dos anos finais do ensino fundamental aparece como objetivo geral a ampliação da compreensão do ambiente natural e social, do sistema político, da economia, da tecnologia, das artes, da cultura e dos valores que fundamentam a sociedade (PPP - EEB Professor Anacleto Damiani, 2018, p.40). Já os objetivos específicos estão articulados à leitura, escrita e interpretação de textos, resolução de problemas e à compreensão de movimentos culturais e diversidade social.

\section{O planejamento anual do professor de Português}

As tecnologias digitais podem ser grandes ferramentas para o professor de Português. Para isso, além de muita (in)formação, é necessário que o professor acredite no resultado positivo que ela pode proporcionar e se alie a ela. As formas de trabalhar atrelado à tecnologia são várias, depende da criatividade, conhecimento e da concepção de Educação e mundo que o professor defende e acredita, pois, não existe uma forma pronta e determinada para ensinar português com o auxílio do aparato tecnológico. 


\section{O Projeto Político Pedagógico e os Planejamentos Anuais de Língua Portuguesa} são os documentos analisados para a discussão do trabalho. Sendo assim, o fazer e o pensar do professor devem estar articulados a esses documentos que orientam as práticas diárias e o planejamento do professor.

No Projeto Político Pedagógico os conteúdos de Língua Portuguesa nos anos finais do ensino fundamental estão organizados por turma, do $6^{\circ}$ ao $9^{\circ}$ ano, conforme tabela abaixo:

Tabela 1: Conteúdos de Língua Portuguesa do Ensino Fundamental (extraída do Projeto PPP da EEB Professor Anacleto Damiani, p. 41, 2018)

\begin{tabular}{|c|c|c|c|}
\hline $6^{\circ}$ ano & $7^{\circ}$ ano & $8^{\circ}$ ano & $9^{\circ}$ ano \\
\hline $\begin{array}{l}\text { Paragrafação } \\
\text { Caligrafia } \\
\text { Identidade e socialização } \\
\text { Linguagem formal e informal } \\
\text { Pontuação } \\
\text { Sinônimo e antônimo } \\
\text { Tempo verbal (passado, presente } \\
\text { e futuro) } \\
\text { Sujeito e predicado } \\
\text { Código e mensagem } \\
\text { Signo, significado e significante } \\
\text { Tipos de frases }\end{array}$ & $\begin{array}{l}\text { Análise linguístico- discur- } \\
\text { siva: } \\
\text { Condições de produção. } \\
\text { Reflexão sobre os elemen- } \\
\text { tos gramaticais linguísticos } \\
\text { (estilísticos) relacionados } \\
\text { aos textos } \\
\text { Coesão e coerência: ên- } \\
\text { fase no sintagma nominal } \\
\text { (pronome, substantivo) e no } \\
\text { sintagma verbal (verbos no } \\
\text { infinitivo, pretérito perfeito e } \\
\text { imperfeito do indicativo), pon- } \\
\text { tuação e acentuação gráfica. }\end{array}$ & $\begin{array}{l}\text { Gêneros textuais sugeridos: } \\
\text { Conto, crônica, poema, canção, } \\
\text { rap (narrar); } \\
\text { Notícia jornalística/entrevista } \\
\text { (relatar); } \\
\text { Estatuto, regulamento (instruir); } \\
\text { Charge, propaganda e propa- } \\
\text { ganda institucional (argumentar); } \\
\text { Seminário, tabela e gráfico (ex- } \\
\text { por). } \\
\text { Análise linguístico-discursiva: } \\
\text { Condições de produção } \\
\text { Reflexão sobre os elementos } \\
\text { gramaticais e linguísticos (esti- } \\
\text { lísticos) relacionados aos textos } \\
\text { Coesão e coerência: ênfase } \\
\text { no sintagma nominal (relações } \\
\text { sintáticas entre artigo, pronome, } \\
\text { numeral, adjetivo e substantivo) } \\
\text { e no sintagma verbal (relação } \\
\text { entre verbo e complemento ver- } \\
\text { bal e predicativo do sujeito). } \\
\text { Frase, oração e período. } \\
\text { Concordância verbal e nominal. } \\
\text { Crase. } \\
\text { Nova ortografia. } \\
\text { Pontuação. } \\
\text { Preposição. }\end{array}$ & $\begin{array}{l}\text { Gêneros textuais sugeridos: pa- } \\
\text { ródia, poema, teatro (narrar); } \\
\text { Reportagem, diário (relatar); } \\
\text { Normas e leis (instruir); } \\
\text { Artigo de opinião, carta de solici- } \\
\text { tação/reclamação (argumentar); } \\
\text { Artigo científico, paper, projeto, } \\
\text { formulário, currículo (expor); } \\
\text { Análise linguístico-discursiva: } \\
\text { Condições de produção. } \\
\text { Reflexão sobre os elementos } \\
\text { gramaticais e linguísticos (esti- } \\
\text { lísticos) relacionados aos textos } \\
\text { Coesão e coerência: ênfase no } \\
\text { sintagma nominal (sujeito) e no } \\
\text { sintagma verbal (predicado) } \\
\text { Colocação pronominal } \\
\text { Classes gramaticais } \\
\text { Uniformidade de tratamento } \\
\text { Entrevista } \\
\text { Linguagem verbal e não verbal } \\
\text { Gêneros Textuais } \\
\text { Crase } \\
\text { Simulado prova Brasil } \\
\text { Crônica e paródia } \\
\text { Conotação e denotação } \\
\text { Nova ortografia }\end{array}$ \\
\hline
\end{tabular}

Fonte: PPP - EEB Professor Anacleto Damiani, p. 41, 2018. 
Dos conteúdos listados, apenas um apresenta-se num modelo que contempla o uso da tecnologia digital, nesse caso o computador, para trabalhar com o gênero textual e-mail. Porém, de modo geral, os conteúdos estão listados e organizados de uma forma que podem ser muito bem articulados às metodologias que contemplam o uso da tecnologia, tendo em vista que a escola possui um laboratório de informática em boas condições e com acesso à internet e, ainda, com outros meios que a escola também possui.

No $6^{\circ}$ ano, por exemplo, as leituras e as produções indicadas podem ser realizadas com o auxílio do computador e a internet, para pesquisa e, após, para a (re)escrita do texto. Pode-se pedir aos alunos que escrevam um texto e que realizem pesquisas sobre as características composicionais do gênero estudado e posteriormente façam adequação ao gênero; é um momento de explorar a criatividade, a autonomia, ensinando-os a utilizar o computador de modo benéfico às suas vidas e, também, de instigá-los a serem pesquisadores.

No $8^{\circ}$ ano, ao trabalhar com os gêneros da esfera jornalística, pode-se utilizar o celular para gravar entrevistas, tendo vista que o uso dessa ferramenta é permitido na escola quando tem finalidade pedagógica e, editar o material para ser apresentado a outras turmas, ou até mesmo, tentar uma parceria com rádio local para expandir o trabalho e, dessa forma, mostrar-lhes que esses meios não servem apenas para acesso às redes sociais, jogos e descontração.

No $9^{\circ}$ ano, pode-se trabalhar com leituras e conhecer a estrutura de artigos científicos acessando a internet, por exemplo - cada um buscando o tema que mais lhe interessa. O currículo, por exemplo, pode ser trabalhado e construído na própria plataforma CNPq e, em seguida, impresso. É uma forma de conhecer a plataforma e aprender organizar o seu próprio currículo, tendo em vista que nessa fase alguns deles já precisam desse documento para ingressarem em algum programa profissional. Utilizar-se de vídeos, músicas, além da própria internet como já foi citado, desperta a atenção dos alunos e trabalha vários sentidos no processo de aprendizagem.

O planejamento anual de português, do ensino fundamental, está orientado pela Proposta Curricular de Santa Catarina e orienta a construir um planejamento que seja de interesse de todos os sujeitos, tendo em vista a formação integral, com diferentes estratégias para diferentes pessoas (Planejamento Anual do Ensino Fundamental da disciplina de Língua Portuguesa, da Escola de Educação Básica Professor Anacleto Damiani, 2018, p.01). 
No desenvolvimento da metodologia, o planejamento anual aponta pequenas estratégias que contemplam o uso da tecnologia na prática docente: trabalho com texto gravado em $\mathrm{CD}$, para que o aluno possa ouvir e escrever - nessa atividade, o aluno pode também gravar, editar e, apresentar seu texto, sua história, e em uma versão mais atualizada, pode-se utilizar o pen drive. Também, no planejamento, aparecem pesquisas na internet que, sim, pode ser uma estratégia bastante positiva do professor de português.

Em sua forma organizacional, como o planejamento é orientado pelo PPP da escola, as demais metodologias vão ao encontro dos objetivos citados nele. Assim, como já mencionado, o professor tem grande possibilidade de incorporar práticas mais atraentes e significativas no seu fazer-pedagógico, mas para isso, é preciso atualizar-se e acreditar que as tecnologias digitais podem ser positivas ao ensino da Língua Portuguesa.

Nos objetivos gerais do planejamento anual do $6^{\underline{0}}$ ano, apresenta-se como proposta, "conhecer os gêneros e-mail, blog e o twitter". No entanto, o verbo conhecer torna-se muito restrito para desenvolver habilidades linguísticas, é necessário aprender, desenvolver, manusear, utilizar, estudar e refletir acerca dessas redes e meios de comunicação.

\section{Considerações Finais}

Fica evidente que os meios tecnológicos podem ser facilitadores e mediadores do conhecimento quando articulados ao planejamento do professor e ao projeto político pedagógico da escola, orientando a proposta de trabalho do professor de língua portuguesa, neste caso, do macro ao micro, partindo da articulação da tecnologia no projeto político pedagógico da escola, que é o documento orientador da instituição de ensino, perpassando o planejamento anual até o diário ou semanal, que orienta diretamente a prática de determinada disciplina.

O ensino de Língua Portuguesa deve ser destinado a preparar o aluno para lidar com a linguagem em suas diversas situações de uso e manifestações, pois o domínio da língua materna não se dá apenas em conhecimentos linguísticos isolados. Partindo desse pressuposto, os professores que têm a tecnologia aliada à sua prática docente desenvolvem uma ação pedagógica diferenciada das totalmente tradicionais, fato que, para os estudantes, possibilita uma melhor compreensão dos 
conteúdos abordados. Além de ser uma ferramenta atrativa, algumas estratégias usadas permitem alcançar os objetivos traçados pelos professores e fazem com que os alunos, ao relacionarem os conteúdos com o cotidiano, percebam o ensino como algo mais significativo.

O desafio do professor autêntico, reflexivo e comprometido com sua prática de ensino é buscar constantemente uma mobilização da gestão no cotidiano da sala de aula, de modo a oferecer um ambiente que promova fascinação, investigação, questionamentos e descobertas. Tal desafio requer acontecimento no sentido de criar e recriar, no espaço do saber, pequenas iniciativas do fazer pedagógico que somadas com o interesse e a participação dos educandos possam alcançar a aprendizagem significativa pelo viés da leitura, da escrita e, do aprendizado da língua materna.

Assim, o ensino do português no contexto da escola de educação básica exige uma metodologia diferenciada capaz de trazer contribuições para a efetivação de ações pedagógicas que despertem no aluno o apreço pelos sentidos e significados que a leitura e as habilidades linguísticas podem lhe propiciar.

Estratégias de leitura utilizadas por professores que incluem a tecnologia na sua ação podem ser essenciais para a aprendizagem dos alunos, pois com elas os docentes podem formar leitores autônomos, capazes de enfrentar os mais variados textos, estabelecendo relações com a sua realidade.

Neste estudo, tendo em vista a proposta desta pesquisa, que visa à reflexão didático-pedagógica quanto à articulação das tecnologias no planejamento do professor de Língua Portuguesa, de modo geral, os conteúdos que estão listados no PPP e nos planejamentos anuais, estão organizados de uma forma que podem ser muito bem articulados às metodologias que contemplam o uso da tecnologia, tendo em vista a estrutura que a escola possui.

Construir alternativas pedagógicas inovadoras atreladas à tecnologia digital é o primeiro passo para a mudança, e a formação necessita de novas estratégias para a construção de um trabalho docente em que ler, escrever, falar, sejam atividades prazerosas, de investigação, de reflexão, de aprendizagem e construção de saberes, que venham a formar um usuário realmente proficiente em sua língua materna.

Nesse sentido, o presente estudo trouxe reflexões que contribuíram com as expectativas do autor, embora a observação feita não tenha sido suficiente para uma total análise. A forma em que os documentos se organizam apontaram mais 
para um alinhamento e escolha dos conteúdos, e não para a didática que orienta a prática deles.

Ao realizar a presente pesquisa, foi possível analisar que a Escola de Educação Básica "A" se apresenta numa estrutura física um tanto positiva para o professor que queira ter a tecnologia digital aliada às suas metodologias e práticas de ensino. Com base nisso, os recursos presentes apontam para uma estrutura positiva que, a partir deles, os professores de português podem desenvolver uma prática mais significativa, atraente e vinculada ao que às crianças e adolescentes esperam das aulas: aprender de forma mais prazerosa, levando em consideração aquilo que é mais presente na vida deles.

Analisando essas possibilidades de tecnologias que a escola possui, o que se percebe é que nos planejamentos anuais e no PPP a articulação que está posta ainda não atende um percentual considerável de uma perspectiva tecnológica de planejar o ensino. Contudo, olhando pelo lado positivo, essa perspectiva de organização de PPP e, principalmente, de planejamento anual, pode-se perceber que ela possibilita uma maior autonomia do professor para organizar suas aulas e da própria flexibilização de trabalhar com conteúdos e metodologias inovadoras.

Os dados encontrados nos documentos analisados confirmaram a possibilidade de utilizar a tecnologia digital no ensino da Língua Portuguesa na Escola de Educação Básica Anacleto Damiani como disponibilidade desses meios na escola. No entanto, para um maior aprofundamento da pesquisa, no intuito de se verificar se está realmente havendo articulação entre tecnologia e ensino, é necessário analisar outros documentos que orientam a prática docente do professor de português, como por exemplo, os planejamentos semanais e diários, também, o acontecimento diário das aulas. 


\section{Technologies in Basic Education: the articulation of digital technology with Portuguese language teaching}

\section{Abstract}

This article presents results of a research about the State School of Basic Education Anacleto Damiani, focusing on "The Articulation of Digital Technology with Portuguese Language Teaching". From Education and Technology, which are landmarks of great influence in contemporary society, teachers face major challenges in their teaching practice, which, in an era of so many technological resources, seeks to diversify their methods to achieve more effective results in their pedagogical practice. However, a significant reflection can be made towards the use of educational technology in the formulation of methodologies for the Portuguese Language curriculum component or in interdisciplinary activities. This is a documental analysis based on the annual plans of the Elementary School of the Portuguese Language subject and the School's Political Pedagogical Project, and focuses on the analysis of the uses of technology in pedagogical practices in Portuguese Language classes, in a state public school of the municipality of Abelardo Luz/SC. It also presents which technologies are present in the school's constitutive space and proposes alternatives/suggestions for their use. The data found point to a significant articulation of the Portuguese Language teacher with the resources present in the school, however, to further deepen this research, it is necessary to analyze the daily practice of Portuguese teachers at the school, or other planning, such as for example, daily or weekly plans, which are organized with a more detailed description of their teaching practices to work and develop skills related to the mother tongue, in this case, the Portuguese language.

Keywords: Education. Technology. Portuguese language.

\section{Notas}

1 Proposta inovadora do governo estadual de Santa Catarina, a qual chegou à Escola de Educação Básica Anacleto Damiani no ano de 2017, como um projeto piloto da escola integral após a reforma do Ensino Médio.

\section{Referências}

BRASIL, MEC, Secretaria de Educação Básica - Departamento de Políticas de Ensino Médio. Orientações Curriculares do Ensino Médio. Brasília, 2004.

BRASIL, Ministério da Educação, Secretaria de Educação Média e Tecnológica. Parâmetros Curriculares Nacionais: ensino médio. Brasília: Ministério da Educação, 2008.

BRASIL. Secretaria da Educação Fundamental. Parâmetros Curriculares Nacionais: terceiro e quarto ciclos: apresentação dos temas transversais, ética. Brasília: MEC/SEF, 1998.

CORRÊA, Juliane. Novas tecnologias da informação e da comunicação: novas estratégias de ensino/aprendizagem. In: COSCARELLI, Carla Viana (Org.). Novas tecnologias, novos textos, novas formas de pensar. Belo Horizonte: Autêntica, 2002. 
KENSKI, Vani Moreira. Educação e tecnologias: O Novo Ritmo Da Informação. São Paulo: Papirus, 2008.

MORAN, José Manuel. A educação que desejamos: Novos desafios e como chegar lá. São Paulo: Papirus, 2007.

PPP. Projeto Político Pedagógico da Escola de Educação Básica Professor Anacleto Damiani. Abelardo Luz, 2017.

SAMPAIO, Marisa Narciso; LEITE, Ligia Silva. Alfabetização tecnológica do professor. Petrópolis: Vozes, 1999.

SOARES, Suely Galli. Ensino Superior e tecnologias educacionais. In: (Org.).Cultura do desafio: gestão de tecnologias de informação e comunicação no ensino superior. São Paulo: Alínea, 2006. 